\title{
Tuzak nöropatiler
}

\section{Entrapment neuropathies}

\author{
Gürsel Leblebicioğlu \\ Hacettepe Üniversitesi Tıp Fakültesi, Ortopedi ve Travmatoloji Anabilim Dalı, Sıhhiye, Ankara, Türkiye
}

\begin{abstract}
Karpal tünel ve kübital tünel sendromu gibi tuzak nöropatilere özellikle üst ekstremitede oldukça sık olarak rastlanır. Supinator sendrom, pronator sendrom ve tarsal tünel sendrom, alt ve üst ekstremitede daha nadir olarak rastlanan ve ayırıcı tanı ve tedavide düşünülmesi gereken diğer tuzak nöropatilerdir. Bu yazıda tuzak nöropati patofizyolojisi ve genel tedavi ilkeleri gözden geçirilecektir.
\end{abstract}

Anahtar sözcükler: periferik sinir; tuzak nöropati; fizyopatoloji; karpal tünel sendromu; kübital tünel sendromu; kompresyon nöropatisi
Entrapment neuropathy syndromes, such as carpal tunnel syndrome or cubital tunnel syndrome, are fairly common problems in the upper extremity. Relatively rarer entrapment neuropathies including supinator syndrome, pronator syndrome or tarsal tunnel syndrome also posess difficulties in differential diagnosis and treatment. In this paper, the basics of the pathophysiology of entrapment neuropathies and the essentials of their treatment has been discussed.

Key words: peripheral nerve; entrapment neuropathy; pathophysiology; carpal tunnel syndrome; cubital tunnel syndrome; compression neuropathy

\section{TANIM}

Tuzak nöropati, motor ve duyu işlev bozuklukları ile seyreden, bireyin yaşam kalitesini ve üretkenliğini derinden etkileyebilen bir mononöropati şeklidir. "Tuzak", "kompresyon" veya benzeri terimler, sorunun başlangıcının sinir kaynaklı olmadığını, dış mekanik etkilere ikincil olarak geliştiğini belirtmek amacı ile kullanılır. Çoğunlukla bir eklem komşuluğunda, anatomik tüneller ve kemik çıkıntıların yakınında seyreden pek çok sinirde görülebilir. Ağrı ve güç kaybı en sık belirtileridir. Romatoid artrit, diyabet, gebelik ve akromegali gibi tıbbi durumlar, tuzak nöropatinin daha çabuk ve daha ağır gelişmesine neden olabilir. Spor, diş hekimliği veya çalgı çalmak gibi benzeri hareketlerin sık ve ardışık olarak tekrarlandığı mesleki uğraşlar da bazı tuzak nöropati tiplerinin belirmesinde etkin olabilir.

\section{DEMOGRAFIK ÖZELLIKLER}

Tuzak nöropati, sık rastlanan bir durumdur; üst ekstremitede daha sıktır. En sık tuzak nöropati, median sinirin karpal tünelde sıkışmasına bağlı olarak gelişen karpal tünel sendromudur. Karpal tünel sendromu prevalansı; Amerika Birleşik Devletleri'nde \%3,72,[1] Hollanda'da $\% 5,8,{ }^{[2]}$ Birleşik Kırallık'ta ise $\% 7^{[3]}$ oranlarında bildirilmektedir. Diğer ülkelerin istatistik verileri göz önünde tutularak, ülkemizde her yıl 100.000'in üzerinde yeni karpal tünel sendromu olgusunun belirdiğini düşünmek, çok hatalı olmayabilir.

\section{ETIYOPATOGENEZ}

Sinir basılarını tedavi eden kişiler, sinir basısı nedeni ile başvuran hastalarda doğru yaklaşımı yapılabilmek için, kronik basıların sinir üzerindeki etkilerini ve bunun fizyopatolojisini bilmek zorundadır.

Periferik siniri oluşturan iki temel unsur vardır. Birincisi aksonlar, ikincisi ise Schwann hücreleri tarafından üretilen miyelin örtüdür. Bu iki unsurda ayrı ayrı veya birlikte oluşan eksiklikler, klinikte periferik nöropati şeklinde görülür. Bir periferik sinirde, farklı demetler oluşturan binlerce akson vardır. Bu aksonların

- İletişim adresi: Prof. Dr. Gürsel Leblebicioğlu, Ortopedi ve Travmatoloji Uzmanı, El Cerrahisi Uzmanı, Willy Brant Sokak 3/4, Çankaya, Ankara, Türkiye Tel: 0544 - 4839065 e-posta: gurselleblebicioglu@ttmail.com

- Geliș tarihi: 13 Ekim $2015 \quad$ Kabul tarihi: 13 Ekim 2015 


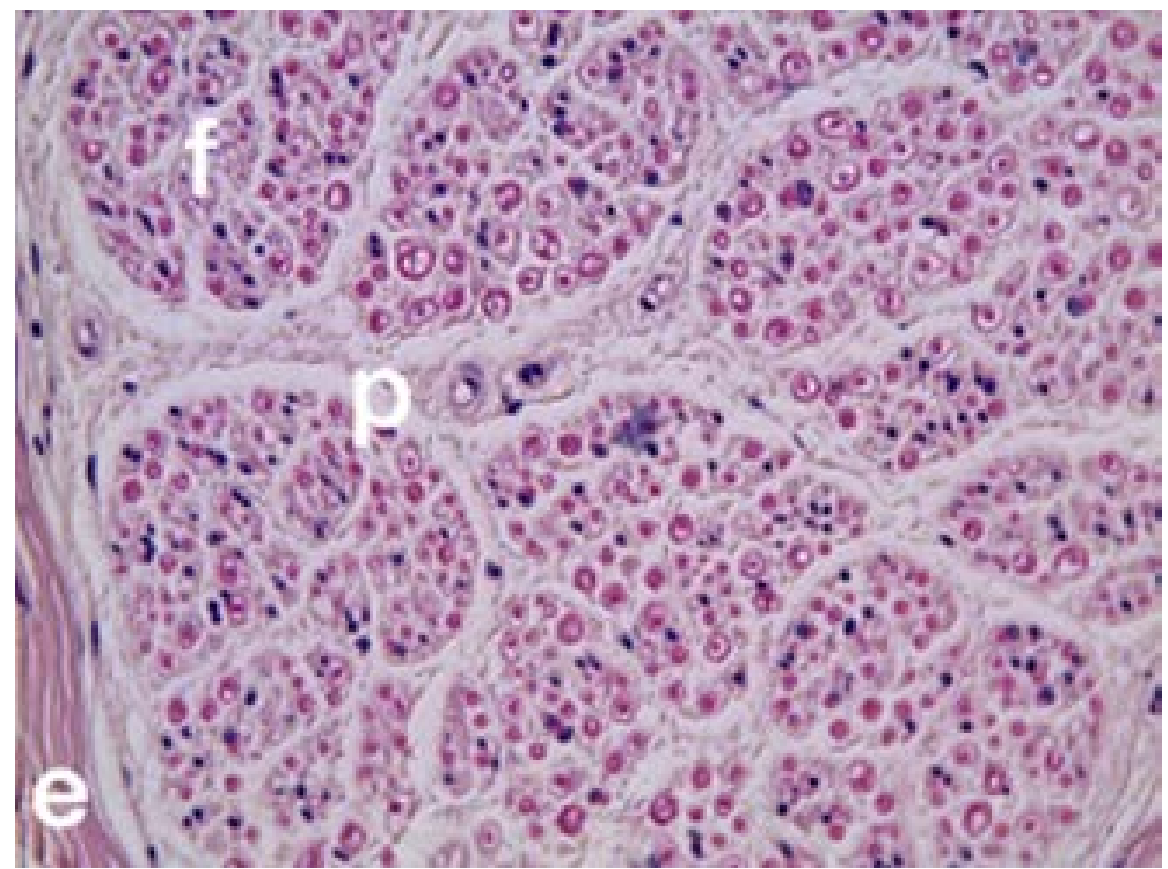

Şekil 1. Periferik sinir kesitinde fasikül grupları (f), epinörium (e) ve perinörium (p) görülmektedir.

bir bölümü yoğun olarak miyelin içerirken, bazıları çok az miyelin içerir (Şekil 1). Akson kaybına bağlı gelişen nöropatilere en iyi örnek, periferik sinir kesileri sonrası oluşan tablodur ve elektrofizyolojik çalışmalarda, sinyal kuvvetinde azalma ile karakterizedir. Miyelin kaybına bağlı gelişen nöropatiler ise Guillain-Barré sendromudur ve elektrofizyolojik olarak sinir ileti hızında azalma ile karakterizedir. Miyelin kaybı ile seyreden nöropatilerde; duyu liflerindeki ileti hızı kaybı, motor liflerdekinden önce gözlenir. Akson kaybının ağırlıklı olduğu nöropatiler, kronik böbrek yetmezliği ve diyabette de görülebilir.

Periferik sinirlerde metabolik aktivitenin yüksek düzeyde olması nedeni ile, kan dolaşımının kesintisiz ve yüksek debili olması gerekir. Ayrıca, özellikle eklem komşuluklarında, çevre dokulardan ayrılarak kayabilmesi gerekir. Bu nedenle, uzun segmentler boyunca çevre dokulardan direkt kan akışı olmasa bile, aksiyel damarlar sayesinde, dolaşımın kesintisiz olarak devam etmesini mümkün kılacak bir damarsal organizasyon dikkat çeker (Şekil 2).

Farklı sinirlerin kronik bası sendromlarında, fizyopatolojik süreçler ile tanı ve tedavi yaklaşımları ortak özellikler taşır. Tuzak veya sıkışma nöropatilerinde patogenezin incelenmesine yönelik, özellikle hayvan modellerin üzerinde, çok sayıda deneysel çalışma yapılmıştır. Bir sinir üzerindeki bası, mikro-sirkülasyonu ve sıvı dinamiğini etkiler. Uygulanan basınç düşük ise, öncelikle venöz geri dönüşü engeller ve venöz staz oluşur. Genel olarak düşük düzeyde ve kronik olarak uygulanan basıların, intranöral ödem oluşmasına ve buna ikincil olarak intranöral basınç artışına neden olduğu söylenebilir. Bu sürecin devam etmesi, kapiller kaçağa ve intranöral ödeme, daha ilerleyen dönemde de miyelin kaybına ve fibrozis belirmesine neden olur. Ortaya çıkan bu etkiler, uygulanan basıncın düzeyi ile bağlantılıdır. Uygulanan basınç ne kadar yüksek ve süresi ne kadar uzunsa, o ölçüde sinir dokusunda değişiklikler gözlenir. ${ }^{[4]}$ Karpal tünelde normal basınç 2,5 $\mathrm{mmHg}$ düzeyindedir. Basıncın $20-30 \mathrm{mmHg}$ arasında olması venöz dönüşe engel olurken, $35-50 \mathrm{mmHg}$ arasındaki basınçlar kapiller akımı azaltır. ${ }^{[5,6]}$ Basınç 70 mmHg'nin üzerinde ise, dolaşım tamamen durur; 30 $\mathrm{mmHg}$ üzerindeki basınç değerlerinde sinir iletisinde bozulma başlar. Basınç ne kadar yüksek ise, histopatolojik değişikliklerin ortaya çıkması o ölçüde erken olur. Daha düşük basınçlarda benzeri histopatolojik özelliklerin gözlenebilmesi için daha uzun bir süre gerekir. ${ }^{[7]}$ Bası ve sonrasında gelişen bölgesel dolaşım yetersizliğinin ilk klinik belirtileri, yüksek hızda ileti gerçekleştiren miyelinli aksonlarda işlev kaybıdır. Özellikle, hafif dokunma, basınç ve vibrasyon duyularında erken dönemde kayıplar gözlenir. Daha ileri dönemlerde, miyelinsiz liflerde de ileti kaybı gözlenir ve bu durum kendini ağıı ve sıcaklık duyusundaki kayıp ile belli eder. 


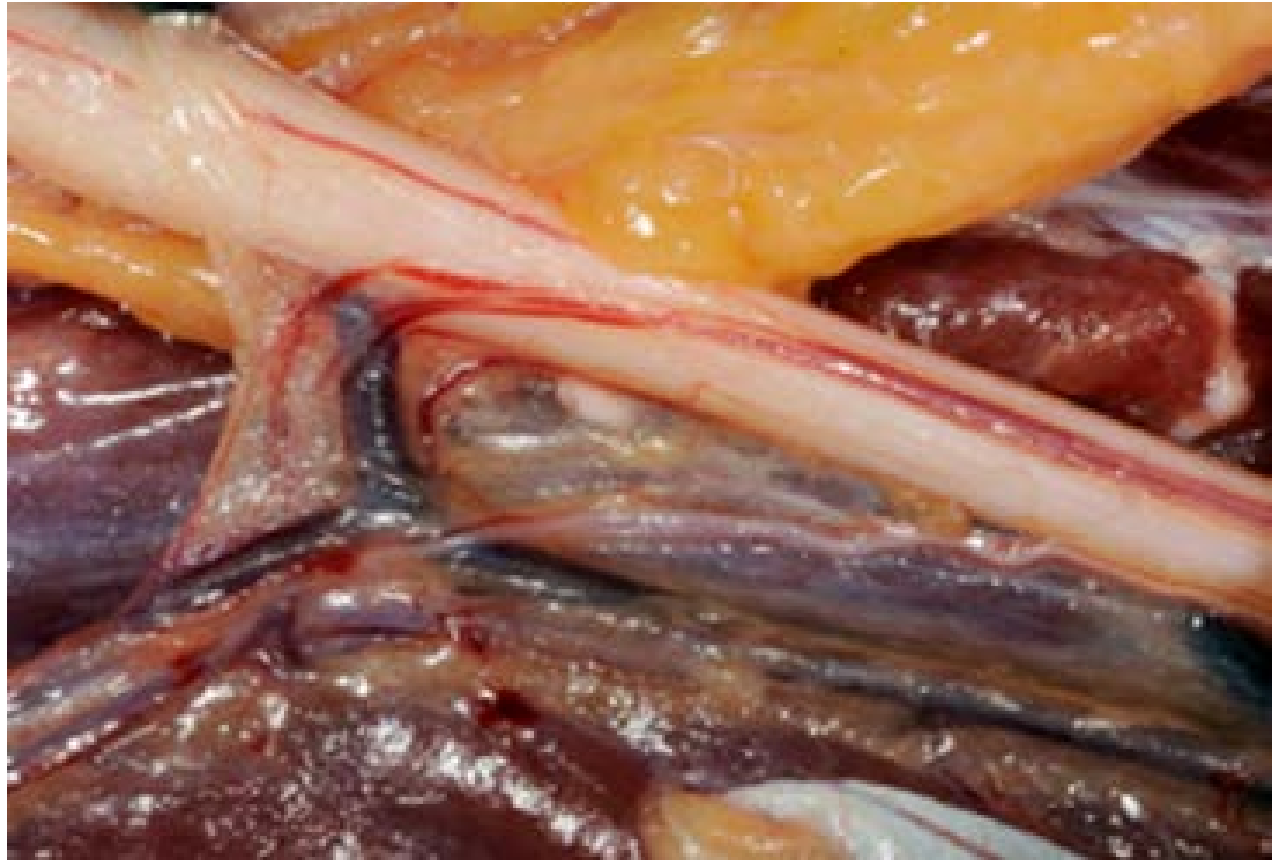

Şekil 2. Ulnar sinirde dirsek düzeyinde damarlanma. Mesonöriumun sinirin ekleme yakın alanlarda çevre dokulara göre hareketli kalmasını sağladığına dikkat ediniz.

Tuzak nöropatilerde, doğal olarak, insana ait histopatolojik materyal elde etme olanağı çok sınırlıdır. Mackinnon ve Dellon'un bir çalışmasında, insan materyalinde perinörial kalınlaşma, demiyelinasyon ve epinöriyal fibrozis geliştiğinden söz edilmektedir. ${ }^{[8]}$ Karpal tünel sendromuna yönelik cerrahi girişimlerde elde edilen sinoviyal biyopsiler üzerinde yapılan histopatolojik incelemeler ise, normal bireylere göre artmış ödem ve fibrozis göstermiştir. ${ }^{[9,10]} \mathrm{Bu}$ iki çalışmada, inflamasyon belirtilerinin az olduğu ifade edilmiştir. Klinik durumları bilinemeyen kadavralar üzerinde yapılan çalışmalarda, periferik sinirlerin, özellikle eklem çevresi düzeylerde, olasılıkla tekrarlayan hareketlere bağlı olarak, artmış bağ dokusuna sahip oldukları düşünülmüş̧tür. ${ }^{[11,12]}$ Tuzak nöropatilerde, dekompresyon sonrası klinik belirtilerin bir bölümü ameliyattan hemen sonra azalabilir. Bazı belirtilerin düzelmesi ise yıllarca sürebilir. Erken dönemdeki düzelmenin nedeni, basının oluşturduğu iskemi etkisinin ortadan kalkması olabilir. ${ }^{[13]}$

Akut ve kronik sinir basılarında, patolojik süreçler birbirlerinden önemli farklılıklar gösterir. Kronik sinir basılarında, sürecin başında demiyelinasyonremiyelinasyon gözlenir. Uzun bir süre akson kaybı oluşmaz. Akson kaybı ve kas atrofisi çoğunlukla sürecin son aşamalarında oluşur. Ayrıca, Schwann hücrelerindeki artış, makrofajlar aracılığı ile değil, doğrudan basının mitojenik etkisi ile oluşur. ${ }^{[14]}$ Makrofajdan arındırılmış modellerde Schwann hücre çoğalmasının görülmesi, bu görüşü destekler. ${ }^{[15]}$

Başta diyabet olmak üzere, obezite, gebelik, tiroid sorunları, aşırı alkol tüketimi, sistemik inflamatuvar süreçler, kronik böbrek yetmezliği ve genel ödeme neden olan hastalıklar, tuzak nöropatiler ile ilişkilendirilmiştir. Güvenilir bir kanıt bulunmamakla birlikte, çalgı çalmak gibi tekrarlayıcı hareketlerin yoğun ve üzün süre yapıldığı mesleki uğraşlar da sinir tuzaklanması açısından dikkati çeken unsurlardandır. ${ }^{[16]}$ Diş hekimliğinde olduğu gibi, uzun süre vibrasyon etkisine maruz kalmakla karpal tünel sendromu gelişmesi arasında bir bağlantı olması mümkündür.[17] Yine diğer bazı mesleklerin, özellikle üst ekstremitede kümülatif travma etkisi oluşturabildiği düşünülmektedir. ${ }^{[18]}$

Diyabet ile birlikte görülen nöropatileri temel olarak iki grupta ele almak mümkündür. Birinci grup; distal, simetrik, asendan/çıkıcı sensoriyomotor tutulum gösteren gruptur. İkinci grup ise, fokal veya multifokal olabilen ve bir veya birkaç sinirinin innerve ettiği alanda denervasyon belirtileri ile kendini gösterir. Bu ikinci grubun vaskülite sekonder iskemi sonucu oluştuğu görüşü vardır.

Nadir olmakla birlikte, pediatrik yaş grubunda tuzak nöropati belirtileri varsa, anatomik farklılıklar ve depo hastalıkları akla gelmelidir. Anomalili lumbrikal 
orijinleri, persistan median arter ve dar karpal kanal, bazı konjenital nedenlerdir. Çocuklarda karpal tünel sendromunun en sık nedeni mukopolisakkaridozlardır.

\section{KLINIK BELIRTILER}

Klinik belirtiler, duyu anormalliklerinden başlayıp, ağrı, parestezi ve motor felçlere kadar değişen bir spektrum gösterebilir. Tuzak nöropatilerde, ilk dönemlerde duyu sorunları ve ağı, sık rastlanılan belirtilerdir; ilerleyen dönemlerde, motor işlev bozuklukları oluşabilir. Klinik değerlendirme sırasında, ilk belirtilerin başladığı zamanın belirlenmesi önemlidir. Duyu bozukluklarının anatomik alanı ve bu bozuklukları arttıran ve azaltan unsurlar belirlenmelidir. Ağrının gece artış göstermesi karakteristiktir. Karpal tünel sendromunda, ağrının uykuyu bölmesi ve elin havada sallanması ile hafiflemesi tanıya yardım edebilir. Güç ve motor koordinasyon kaybı belirtileri olabilir. Otomobil kullanırken uyuşma ve güç kaybı oluşması karpal tünel sendromunda gözlenebilir. Telefonla konuşma sırasında elin ulnar tarafında ağrı gözlenmesi, kübital tünel sendromunun bir özelliğidir. Keman sanatçılarında arşe kontrolünde yaşanan zorluk, posterior interosseöz sinirin supinator arkadda tuzaklanmasının bir belirtisi olabilir. Banka kartlarının bankamatik cihazlarından çıkartılması sırasında güçsüzlük olması, anterior interosseöz sinir sorununu gösterebilir. Saç bakımı sırasında veya mutfak işlerinde olduğu gibi, elin baş üstünde tutulması ile veya uzun süre omuzdan askılı çanta taşınmasın sonrasında oluşan ağrı ve parestezi, torakal çıkış sendromunda gözlenebilir.

Üst ekstremite için fizik muayene, boyun ve omuz bölgesini de içerir. Aynı şekilde, alt ekstremite sinirlerinin değerlendirilmesi, bel ve kalça bölgelerini de içerir. Denerve ciltte kuruluk ve viskoelastik davranış farklılığı gözlenir. ${ }^{[19]}$ Skapulanın pozisyonu ve hareket özelliklerine dikkat edilir. Serratus anterior zayıflığında, skapular kanatlanma gözlenir. Trapezius kası disfonksiyonu, skapulada diskinetik özellikler ortaya çıkarır. El ve dirsekte anormal postür olup olmadığına bakılır. Muayeneye ölçülebilir değerler katmak için monofilament testi, iki nokta ayırımı testi, pinç ve grip gücü ölçümü ve kas gücü değerlendirmeleri yapılır. Cilt duyusu eşik değerini test etmek için kullanılan SemmesWeinstein monofilament testinde, 2.83 monofilamentinin hissedilmesi normaldir. İki nokta ayırımı testinde, birbirine $6 \mathrm{~mm}$ 'den uzak iki noktanın ayrı ayrı algılanamaması anormaldir.

Değerlendirilmesi yapılan sinir proksimalden distale doğru palpe edilerek, aşıı duyarılı olduğu bir bölge varsa, bunun belirlenmesi çok değerlidir. Duyarlı bölgeye basınç uygularken, Durkan testinde olduğu gibi, bası süresi uzadıkça ağrı veya parestezinin artması, tuzak nöropati yönünden anlamlı olabilir. Hassasiyetin en belirgin olduğu yerde ve distalinde Tinel bulgusu aranır. Periferik sinir sorunlarında klinik bulgular dar bir alanda belirgin ise ve elektrodiyagnostik çalışmalar bu alanı işaret ediyorsa, tanı ve tedaviye yön vermek zor olmaz. Yaygın belirtileri olan ve elektrodiyagnostik çalışmaların belirli bir alanı işaret etmediği hastalara yaklaşım şeklinin belirlenmesi zor olabilir. Dikkatli bir palpasyonla hassasiyet aranması gereken alanlar şu şekilde özetlenebilir:

Üst ekstremite

- C5, C6 kök düzeyi

- Supraklaviküler çukur, torakal çıkış bölgesi, alt trunkus

- Kostoklaviküler aralık

- Aksiller bölge

- Supraskapular çentik düzeyi

- Lateral intermusküler septum, humerus 1/3 proksimal-orta düzeyi

- Mediyal intermusküler septum, mediyal epikondilden $8 \mathrm{~cm}$ prokimalde Struthers arkadı

- Struthers ligamenti düzeyi

- Pronator arkad - FDS arkadı

- Supinator arkad-radyal tünel

- Karpal tünel

- Kübital tünel proksimalden distale

- Guyon kanalı

\section{Alt Ekstremite}

- Lumbosakral intervertebral aralıklar

- Anterior superior iliak çıkıntı bölgesi

- Siyatik çentik

- Priformis kası düzeyi

- Fibula boynu düzeyi

- Tarsal tünel üzeri

- Navikula inferioru

- Intermetatarsal bölgeler

\section{TANI VE AYIRICI TANI}

Elektrofizyolojik değerlendirmeler, tuzak nöropatilerin değerlendirilmesi ve tedavisine yön verilmesi açısından değerlidir; kliniktanının doğrulanması ve olası diğer sorunların dışlanması konularında çok yararlı olabilir. Duyu korunmuş olmasına rağmen motor işlev bozukluğu ve kas atrofisi belirgin olan hastalarda; motor nöron hastalıkları, amiyotropik lateral skleroz ve omurilik 
sorunlarının irdelenmesi açısından elektrofizyolojik değerlendirme yapılır. Bu, periferik sinirde lezyon düzeyinin belirlenmesinde de yararlı olabilir. Elektrofizyolojik değerlendirmeler, radyal sinir ve posterior interosseöz sinir lezyonlarının, median sinir ve anterior interosseöz sinir lezyonlarının ya da kök basılarının ayırt edilebilmesinde kullanılır. Motor aksiyon potansiyelleri, akut kompresyona bağlı nöropatilerde kaybolurken, kronik tuzak nöropatilerde, özellikle erken dönemlerde korunur. Tuzak nöropatilerin erken döneminde yalancı negatif sonuçlar gözlenebilir. Kas denervasyonunun elektromiyografi (EMG) bulguları, fibrillasyonlar, pozitif keskin dalgalar ve fasikülasyonlardır.

Son dönemde, yüksek çözünürlüklü ultrasonografi ve manyetik rezonans görüntüleme ${ }^{[20,21]}$ yöntemleri güncellik kazanmıştır. Görüntüleme yöntemlerine, özellikle proksimal lezyonlarda artan sıklıkla başvurulmaktadır. Sıkışma düzeyinin proksimalinde sinirin şişkin görünmesi, buna karşın sıkışma düzeyinde çapının azalması karakteristiktir. Bu görüntüleme yöntemleri, sinir komşuluğunda yer kaplayan ve sinire bası yapan lezyonların belirlenmesinde önemli veriler sağlar.

Bir sinire birden fazla bölgede bası olabilir. Bir aksona bir bölgede bası olması, aksonun bütün boyunca basıya duyarlılığını arttırır. Bu durumda, bu iki bası noktası, birbiri üzerine eklenen bir etki gösterebilir. ${ }^{[22]}$ Tek tek klinik belirti vermeyecek derece hafif basılar birlikte gelişirse, klinik bulgular oluşabilir. Bu sürece çift/çoklu ezilme "double crush" denir ${ }^{[23]}$ ve aksonlarda, dinein bağlantılı retrograd taşınma ve kinesin bağlantılı anterograd taşınmanın her iki bası alanında sekteye uğraması ile açıklanır. Ayrıca, periferik sinirlerin mekanik etkilere karşı dayanıklılığını azaltan diyabetik nöropati, nörolojik hastalıklar ve basınç nöropatilerine yatkınlığa neden olan genetik hastalıklar gibi süreçler, çift ezilme belirtilerini arttırabilir. Periferik miyelin proteinlerini kodlayan genlerdeki delesyonlar, segmental olarak miyelin kaybına ve sensoriyomotor sinir disfonksiyonuna neden olabilir. Böyle bir durumda, sinirlerin basınca dayanıklılığında azalma, fokal duyu ve motor kayıplar, tendon reflekslerinde azalma ve pes cavus gibi deformiteler görülebilir.

Çift/çoklu ezilme belirtileri gösteren hastalarda tedavi yaklaşımları ile ilgili farklı görüşler vardır. Basının gözlendiği tüm noktaların dekompresyonu yapılmadığı sürece, klinik düzelme gözlenmeyebilir. Tek cerrahi seansta tüm bası noktaları ele alınabileceği gibi, aşamalandırılmış cerrahi girişimler de gerçekleştirilebilir. Öncelikle karmaşık olmayan cerrahi girişimler gerçekleştirildikten sonra, yeterli düzelme gözlenmez ise daha karmaşık girişimlere yönelmek, akılcı bir yaklaşım olur. Örneğin, torakal çıkış sendromu ve kübital tünel sendromu belirtileri ile gelen bir hastada, ilk aşamada kübital tünel sendromuna yönelik girişim yapıldıktan sonra, torakal çıkış bölgesinde cerrahi işlemleri klinik belirtilerde yeterli düzelme görülmez ise uygulamak bir seçenek olabilir. Servikal kök basısı ve karpal tünel bulguları ile başvuran hastalarda, karpal tünel düzeyinde median sinir dekompresyonu sonrası servikal kök basısı belirtilerinde hafifleme olması nadir değildir.

\section{TEDAVi}

Tuzak nöropatilerin tedavisinde, konservatif ve cerrahi yaklaşımlar olabilir. Motor işlev bozukluğu, özellikle elektrodiyagnostik çalışmalar ile destekleniyor ise, cerrahi girişim için en temel göstergedir. Motor işlev bozukluklarının belirmediği tuzak nöropatilerde ise cerrahi dışı yöntemlere başvurulur. ${ }^{[24]}$

\section{GELECEK}

Periferik sinir lezyonlarında en önemli sorun, sinir rejenerasyonu gerçekleşene dek hedef dokularda geri döndürülemez değişikliklerin oluşmasıdır. ${ }^{[25]}$ Kas dokusunun denerve kaldığı süre içinde, nöromusküler bileşkenin $^{[26]}$ ve sarkomerik organizasyonun korunması ile ilgili yöntemlerin geliştirilmesi en önemli hedeflerdendir. Kronik basıya bağlı gelişen nöropatilerde, aksondan çok miyelin kılıf kaybı olması, mekanik uyarılar ile Schwann hücresi artışı arasındaki bağlantının ayrıntılı olarak araştırılması gereğini ortaya çıkarıyor. Miyelin kılıf stabilizasyonunu sağlayabilecek farmakolojik ajanlar, ağrı kontrolünde büyük katkı sağlayabilir.

\section{KAYNAKLAR}

1. Thoma A, Veltri K, Haines T, Duku E. A meta-analysis of randomized controlled trials comparing endoscopic and open carpal tunnel decompression. Plast Reconstr Surg 2004;114(5):1137-46.

2. de Krom MC, Knipschild PG, Kester AD, Thijs CT, Boekkooi PF Spaans F. Carpal tunnel syndrome: prevalence in the general population. J Clin Epidemiol 1992;45(4):373-6.

3. Ferry S, Pritchard T, Keenan J, Croft P, Silman AJ. Estimating the prevalence of delayed median nerve conduction in the general population. BrJ Rheumatol 1998;37(6):630-5.

4. Rempel DM, Diao E. Entrapment neuropathies: pathophysiology and pathogenesis. J Electromyogr Kinesiol 2004;14(1):71-5.

5. Dahlin LB, Lundborg $G$. The neurone and its response to peripheral nerve compression. J Hand Surg $\mathrm{Br}$ 1990;15(1):5-10.

6. Rempel D, Dahlin L, Lundborg G. Pathophysiology of nerve compression syndrome: response of peripheral nerves to loading. J Bone Joint Surg Am 1999;81(11):1600-10.

7. Diao E, Shao F, Liebenberg E, Ishiko T, Rempel D, Lotz, J. Carpal tunnel syndrome. A dose response relationship between pressure and time in an animal model. 46th Annual Meeting, Orthopaedic Research Society, March 12-15, 2000, Orlando, Florida. http://www.ors.org/Transactions/46/0144.pdf 
8. Mackinnon SE, Dellon AL, Hudson AR, Hunter DA. Chronic human nerve compression -a histologic assessment. Neuropathol Appl Neurobiol 1986;12(6):547-65.

9. Kerr CD, Sybert DR, Albarracin NS. An analysis of the flexor synovium in idiopathic carpal tunnel syndrome: a report of 625 cases. J Hand Surg Am 1992;17(6):1028-30.

10. Schuind F, Ventura M, Pasteels JL. Idiopathic carpal tunnel syndrome: histologic study of flexor tendon synovium. J Hand Surg Am 1990;15(3):497-503.

11. Armstrong TJ, Castelli WA, Evans FG, Diaz-Perez R. Some histological changes in carpal tunnel contents and their biomechanical implications. J Occup Med 1984;26(3):197-201.

12. Sunderland S. Nerves and Nerve Injuries, 2nd ed. London: Churchill Livingstone; 1978. p.1-13.

13. Okutsu I, Ninomiya S, Hamanaka I, Kuroshima N, Inanami $\mathrm{H}$. Measurement of pressure in the carpal canal before and after endoscopic management of carpal tunnel syndrome. J Bone Joint Surg Am 1989;71(5):679-83.

14. Gupta R, Steward O. Chronic nerve compression induces concurrent apoptosis and proliferation of Schwann cells. J Comp Neurol 2003;461(2):174-86.

15. Gray M, Palispis W, Popovich PG, van Rooijen N, Gupta R. Macrophage depletion alters the blood-nerve barrier without affecting Schwann cell function after neural injury. J Neurosci Res 2007;85(4):766-77.

16. Ettema AM, Amadio PC, Zhao C, Wold LE, O'Byrne MM, Moran SL, An KN. Changes in the functional structure of the tenosynovium in idiopathic carpal tunnel syndrome: a scanning electron microscope study. Plast Reconstr Surg 2006;118(6):1413-22.

17. Wieslander G, Norbäck D, Göthe CJ, Juhlin L. Carpal tunnel syndrome (CTS) and exposure to vibration, repetitive wrist movements, and heavy manual work: a case-referent study. Br J Ind Med 1989;46(1):43-7.
18. Latko WA, Armstrong TJ, Franzblau A, Ulin SS, Werner RA, Albers JW. Cross-sectional study of the relationship between repetitive work and the prevalence of upper limb musculoskeletal disorders. Am J Ind Med 1999;36(2):248-59.

19. Fırat T. Periferik Sinir Lezyonlarında Motor, Duyu, ve Otonomik Fonksiyonların Değerlendirilmesi. Doktora Tezi. Hacettepe Üniversitesi Sağlık Bilimleri Enstitüsü. Ankara: 2005.

20. Andreisek G, Crook DW, Burg D, Marincek B, Weishaupt D. Peripheral neuropathies of the median, radial, and ulnar nerves: MR imaging features. Radiographics 2006;26(5):1267-87.

21. Kim S, Choi JY, Huh YM, Song HT, Lee SA, Kim SM, Suh JS. Role of magnetic resonance imaging in entrapment and compressive neuropathy -what, where, and how to see the peripheral nerves on the musculoskeletal magnetic resonance image: part 2. Upper extremity. Eur Radiol 2007;17(2):509-22.

22. Mackinnon SE. Double and multiple "crush" syndromes. Double and multiple entrapment neuropathies. Hand Clin 1992;8(2):369-90.

23. Upton AR, McComas AJ. The double crush in nerve entrapment syndromes. Lancet 1973;2(7825):359-62.

24. Fox IK, Mackinnon SE. Adult peripheral nerve disorders: nerve entrapment, repair, transfer, and brachial plexus disorders. Plast Reconstr Surg 2011;127(5):105e-118e. CrossRef

25. Carter AJ, Kristmundsdottir F, GilmourJ, Glasby MA. Changes in muscle cytoarchitecture after peripheral nerve injury and repair. A quantitative and qualitative study. J Hand Surg $\mathrm{Br}$ 1998;23(3):365-9.

26. Mozaffar T, Strandberg E, Abe K, Hilgenberg LG, Smith MA, Gupta R. Neuromuscular junction integrity after chronic nerve compression injury. J Orthop Res 2009;27(1):114-9. CrossRef 